\title{
TERJERAT (CINTA TERLARANG OLEH LATAR BELAKANG DAN KETURUNAN)
}

\author{
Isra Fahriati \\ Universitas Syiahkuala Banda Aceh \\ e-mail : israfahriati@gmail.com \\ Diterima: 18 Agustus 2018. Disetujui : 8 November 2018. Dipublikasikan : 1 Desember 2018

 \\ ()2018 - DESKOVI Universitas Maarif Hasyim Latif. Ini adalah artikel dengan akses terbuka di \\ bawah lisensi CC BY 4.0 (https://creativecommons.org/licenses/by/4.0/)
}

\begin{abstract}
ABSTRAK
Karya tari terjerat ini terinspirasi dari kisah empiris dari sahabat penulis. Sahabat penulis menceritakan bagaimana kehidupan rumah tangganya yang belum lama terjalin. Pernikahan yang tidak didasari cinta kini membuat huubungan pernikahaannya penuh dengan tekanan batin. Rasa menyesal dan terpukul karena harus meniggalkan sang kekasihnya yang berasal dari masyarakat biasa hanya karena sebuah aturan adat dari keluarga bangsawan. Pengalaman pribadi kerap menjadi rangsangan dalam menciptakan sebuah karya. Hal inilah yang mendorong penulis untuk menciptakan sebuah koreografi yang bertujuan menyampaikan kepada masyarakat dengan menggunakan tubuh sebagai alat penyampaian fenomena tersebut. Karya tari terjerat diwujudkan dengan beberapa medium salah satunya adalah medium gerak, penulis menggunakan gerak metakinesis, fisik dan psikis adalah dua aspek yang memeiliki hubungan yang erat dengan pengalaman pribadi, mental dan peralatan emosional. Karya tari ini melibatkan empat orang penari diantaranya satu penari laki-laki dan tiga penari perempuan. Karya tari ini ditampilkan pada pentas proscenium. Bentuk dari koreografi tersebut bersifat literal dan menggunakan tipe tari dramatic. Tari ini menggunakan metode penciptaan koreografi dan kreativitas.
\end{abstract}

Kata kunci: adat, golongan, status sosial

\section{ABSTRACT}

This terjerat dance work is inspired by empirical stories from the writer's best friend. A friend of the writer tells how his married life. Marriage that is not based on love now makes the marriage relationship full of inner pressure. feeling sorry that because I had to leave her lover who came from an ordinary people just because of a customary rule from a noble family. Personal experience is often a stimulus in creating a work. This is what encourages the writer to create a choreography that aims to convey to the community by using the body as a means of delivering the phenomenon. Terjerat dance manifested in several mediums, one of which is the medium of motion, the author uses metacinesis, physical and psychological movements are two aspects that have a close relationship with personal experience, mental and emotional feeling. This dance involved four dancers including one male dancer and three female dancers. This dance is performed on the proscenium stage. The form of the choreography is literal and uses a dramatic type of dance. This dance uses the method of choreography creation and creativity.

Keywords: culture, faction, social status

\section{PENDAHULUAN}

Status sosial, keturunan, dan kasta kerap menjadi sebuah syarat dalam penentuan pasangan hidup. Adapun cinta terkadang berhadapan dengan aturan yang dianut oleh suatu masyarakat, khususnya pada masyarakat Aceh. Sebuah keluarga bangsawan diharuskan menikah dengan keluarga yang berasal dari derajat yang sama pula. Teuku dan Cut merupakan gelar bangsawan pada masyarakat Aceh. Teuku adalah gelar bangsawan untuk kaum pria, sedangkan Cut adalah gelar bagi kaum wanita. Pernikahan kedua keluarga bangsawan ini dipercaya tidak akan menghilangkan garis keturunannya, karena hanya seorang wanita dari keluarga bangsawan yang menikah dengan seorang pria bergelar Teuku, yangdapat memberikan keturunandengan kedua gelar tersebut.Gelar Cut dan Teuku merupakan gelar yang diberikan berdasarkan sistem monarki tersebut menjadi simbol yang menunjukkan bahwa seseorang itu memiliki garis keturunan yang erat dengan kerajaan Aceh. 
Keharusan bagi seorang wanita Aceh yang bergelarkan Cut untuk menikah dengan seorang pria yang bergelar Teuku untuk dapat memperbesar angka keturunan yang bergelar bangsawan Aceh. Begitu pula pria yang bergelar Teuku untuk harus menikah dengan wanita yang bergelar $C u t$, karena pada zaman kesultanan mereka percaya bahwa Cut menujukan sebuah keluarga dari status sosial tinggi.

Seiring perubahan zaman, aturan adat istiadat pernikahan sesama keluarga bangsawan di Aceh tidak lagi diterapkan sebagaimana mestinya pada masa lalu. Para Teuku tetap dapat mewariskan gelar bangsawan kepada anak cucunya walaupun tidak bersisterikan Cut dan bisa menikah dengan wanita manapun, asalkan wanita tersebut memiliki akhlak yang baik dan taat pada agama islam. Berbeda halnya dengan wanita yang memiliki gelar $C u t$ harus menikah dengan seorang pria yang memiliki gelar Teuku, karena apabila tidak, maka gelar bangsawan tidak dapat diwariskan kepada anak cucunya.

Penulis memiliki seorang sahabat yang pernah datang berkunjung untuk berbagi keluh kesahnya. Sahabat penulis menceritakan bagaimana kehidupan rumah tangganya yang belum lama terjalin. Pernikahannya yang tidak didasari cinta kini membuat hubungan pernikahannya penuh dengan tekanan batin. Hal inilah yang mendorong seorang koreografer untuk menciptakan sebuah koreografi yang bertujuan menyampaikan kepada masyarakat dengan menggunakan tubuh sebagai alat untuk menyampaikan fenomena tersebut. Cerita tersebut adalah sebuah inspirasi munculnya gagasan, sehingga penulis ingin mewujudkannya ke dalam sebuah penciptaan karya tari yang berjudul Terjerat.

\section{METODE PENELITIAN}

Langkah dalam penciptaan karya tari Terjerat ini mengacu pada pendapat Martinus Miroto dalam buku yang berjudul Karya Cipta Seni Pertunjukan editor Yudiaryani, et.al (Yudiaryani, 2017). Dalam buku tersebut Miroto menawarkan tahapan desain riset artistik-koreografi yaitu perumusan gagasan awal, perancangan, eksplorasi-improvisasi, komposisievaluasi dan presentasi-dokumentasi.

\section{PEMBAHASAN}

Rancangan karya tari dapat membantu atau mempermudah kerja dalam melakukan proses penciptaan. Berikut rancangan yang dipersiapkan:

\section{Tema tari}

Penciptaan karya tari ini menggunakan pendekatan tema literal. Tema literal bersifat naratif, biasanya digunakan dalam pertunjukan tari yang menggambarkan tetang cerita dongeng, sejarah, cerita rakyat, pengalaman pribadi, interpretasi karya fiksi, dan lain sebagainya.

\section{Judul Tari}

Judul yang dipilih dalam karya ini adalah Terjerat. Judul tersebut dimaksud dapat memberi gambaran tentang adanya cara pandang yang berbeda dari seorang wanita dalam mempertahankan ideologi dan intergritas.

\section{Tipe Tari}

Karya tari Terjerat menggunakan tipe tari dramatik yang mengandung arti bahwa gagasan yang diungkapkan sangat kuat dan penuh daya pikat, dinamis, juga lebih memusatkan perhatian pada sebuah kejadian atau suasana dan tidak mengelaran cerita secara naratif.

\section{Mode Penyajian tari}

Mode penyajian tari dalam karya ini adalah representasional yaitu menggambarkan suatu kenyataan yang sesuai dengan gerak yang secara langsung dapat dikenali maknanya.

\section{Dramaturgi}

Tari ini menggunakan dramaturgi Fragmented yang merupakan struktur dramatik yang menerapkan teknik penyusunan bagian-bagian dalam cerita secara tidak berurutan.

\section{Gerak Tari}

Gerak yang digunakan adalah gerak sehari-hari (realis) dan simbolis (stilisasi). Selain itu koreografer juga menggunakan gerak-gerak tari modern seperti salto, gerak menggulingkan badan, gerak kayang, gerak split, dan gerak butterfly.

\section{Penari}

Penyajian tari Terjerat ini menggunakan koreografi kelompok yang terdiri dari tiga orang penari perempuan dan satu orang penari laki-laki.

\section{Musik}

Karya tari ini mengunakan iringan recording berdurasi 25 menit, karya Amris Siwen Ariga seorang komposer lulusan prodi pengkajian musik di Program Pascasarjana Institut Seni Indonesia Yogyakarta.

\section{Tata rias dan Busana}

Rias yang digunakan adalah tatarias wajah natural. Sedangkan kostum penari terdiri dari pakaian terusan panjang berwarna putih yang menyimbolkan kebebasan serta memiliki kekuatan.

\section{Tata Cahaya}

Tata cahaya dalam karya tari ini memiliki peran sebagai pembentuk suasana dan berfungsi sebagai penguat adegan dan sebagai alat untuk memperkuat simbol bentuk tubuh penari.

\section{Properti \\ Kain kuning pada karya tari Terjerat ini digunakan sebagai simbol hukum/ aturan-aturan}


khusus yang diakui dan dijaga oleh sekelompok masyarakat tertentu

Kupiah Meuketop (topi pengantin laki-laki Aceh) dalam tarian ini digunakan sebagai simbol lelaki bangsawan Aceh.

\section{Pesan yang disampaikan}

Pesan yang ingin disampaikan dalam karya tari Terjerat adalah sebuah bentuk nilai keiklasan seorang wanita yang yakin bahwa keinginan tidak selamanya akan menciptakan kebahagiaan, melainkan takdir adalah yang terbaik bagi hidupnya.

\section{Perwujudan Penciptaan Karya}

Karya tari Terjerat terbagi menjadi enam segmen. Masing-masing segmen pada tari ini berdiri sendiri, lalu akan disatukan pada sebuah rangkaian peristiwa. Struktur dramatik karya tari ini meliputi:

\section{Segmen 1: Sorot Balik}

Segmen ini menggambarkan sebuah kenangan masa lalu wanita yang sedang dimabuk asmara. Jatuh cinta adalah hal yang terasa menyenangkan dan membahagiakan bagi siapun yang merasakannya. Segala sesuatu tampak indah saat kita sedang terkena sindrom tersebut. Bagi kaum wanita, jatuh cinta merupakan hal yang lumbrah saat mereka menyukai seorang pria yang masuk ke dalam tipe idealnya. Seorang wanita yang sedang jatuh cinta lebih bisa menyimpan perasaannya, walaupun demikian sikap wanita yang sedang dimabuk asmara akan terlihat dari gerak gerik dan bahasa tubuhnya. Semua kenangan indah itu terasa sangat membahagiakan saat dikenang kembali, namun rasa penyesalan hadir ketika wanita ini menyadari bahwa semua itu hanyalah masa lalu yang tidak bisa diulang kembali.

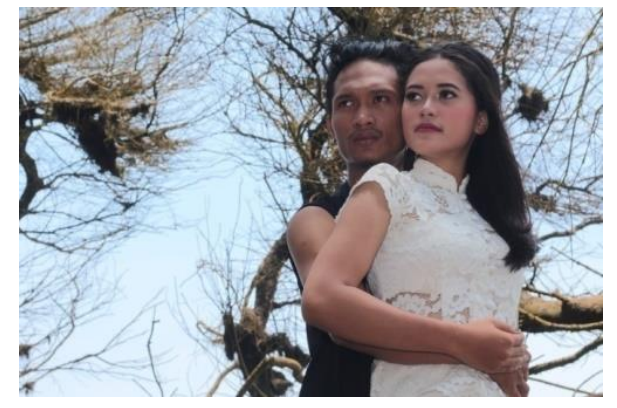

Gambar 1.Segmen 1 sorot balik

\section{Segmen 2: Perjuangan}

Segmen ini mewujudkan tentang perjuangan seorang wanita yang ingin menggapai sebuah kebebasan dari aturan yang menjeratnya. Bagaimana kerasnya usaha wanita tersebut untuk mempertahankan sebuah perjuangan cinta. Perlakuan tersebut digambarkan dengan gerak yang saling menghalangi langkah kaki, gapaian tangan dan tubuh yang dilakukan oleh dua orang penari wanita. Kemudian diikuti dengan gerakan saling tolak menarik seolah-olah bagian yang menarik adalah simbol dari batasan-batasan atau aturan yang menghalangi keinginannya. Sementara yang menolak adalah simbol dari perlawanan yang ingin keluar dari aturan tersebut.

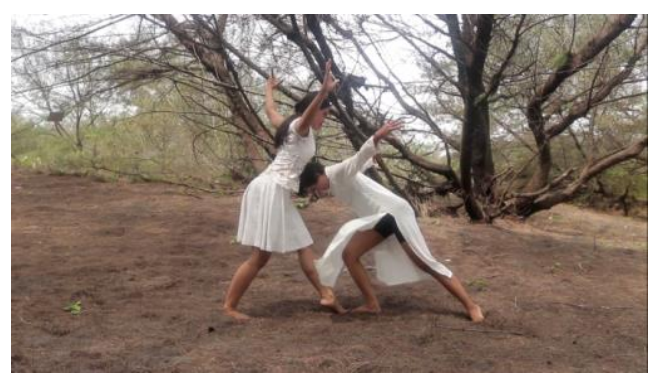

Gambar 2.Segmen 1 perjuangan

\section{Segmen 3: Tarik Ulur}

Segmen ketiga menggambarkan tentang seorang wanita dan pria yang sedang memadu kasih. Seketika mereka sadar bahwa mereka tidak mungkin bersatu karena sebuah aturan keluarga wanita yang sudah mendarah daging. Satu sisi mereka ingin berpisah karena tidak akan bisa melanjutkannya cinta mereka ke tingkat pernikahan, namun hati mereka sama-sama tidak ingin melepaskan satu dan yang lainnya.Peristiwa tersebut diwujudkan dengan satu orang penari pria dan satu orang penari wanita. Penari wanita bergerak menjauh, lalu penari wanita tidak membiarkannya dengan mendekapnya. Kemudian penari pria berusaha berlari ke arah berlawanan dari wanita, namun penari wanita ikut mengejarnya.

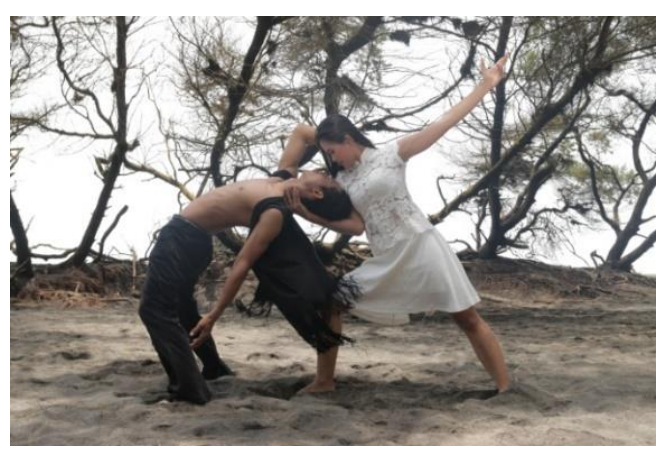

Gambar 3.Segmen 3 tarik-ulur

\section{Segmen 4: Pertentangan}

Perbedaan golongan masyarakat sering menjadi pro dan kontra, terutama dalam masalah perkawinan.Persoalan perkawinan adalah persoalan yang selalu aktual dan selalu menarik untuk dibicarakan, karena persoalan ini bukan hanya menyangkut tabiat dan hajat hidup manusia yang asasi saja tetapi juga menyentuh suatu lembaga yang luhur dan sentral yaitu rumah tangga. Dalam sebuah lingkungan masyarakat pasti ada sebuah aturan yang diberlakukan untuk sebuah kriteria dari kedua calon pengantin. Dalam segmen ini penyaji menggambarkan 
peristiwa tidak akan bersatunya sepasang kekasih karena darah saibatin selalu biru. Bentuk gerak dalam segmen ini diwujudkan oleh dua orang penari wanita dan satu penari pria. Saat laki-lakiingin mendekat ke zona yang dilarang, ia selalu ditahan oleh kedua orang penari wanita dengan cara menggangkatnya dan menjauhkannya.



Gambar 4.Segmen 4 pertentangan

\section{Segemen 5: Terjerat}

Tak ada yang tahu kapan datangnya cinta dan tidak ada yang tahu kamu akan jatuh cinta pada siapa. Namun bagaimana jika cinta yang datang kadang bisa menjadi musibah ketika kamu terjebak dengan aturanaturan yang berlaku? karena bagaimanapun pada akhirnya kamu maupun dirinya akan berakhir pada sesuatu yang salah. Segmen ini menggambarkan tentang peristiwa terjerat karena aturan-aturan yang berlaku di dalam lingkungan sosial. Peristiwa ini digambarkan dengan properti yang melilit penari wanita. Properti diibaratkan sebagai simbol dari aturan adat yang pada akhirnya harus ditaati. Properti ini juga sebagai sebuah penghalang bagi penari wanita, dan dapat membatasi gerak-gerak pemberontakan. Properti ini digunakan pula oleh salah satu penari pria, sebagai simbol pembatas akan tidak pantasnya pria ini dengan wanita dari golongan berdarah biru.

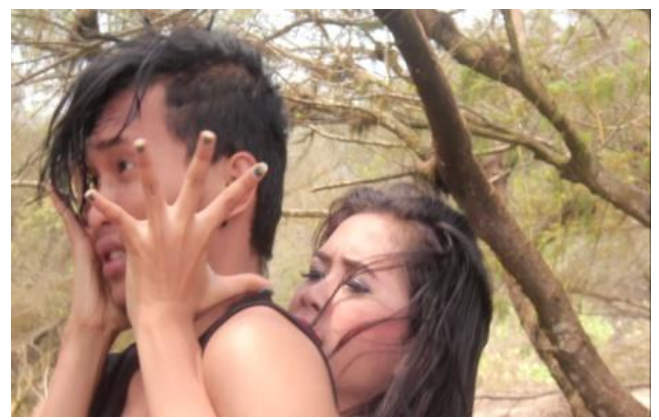

Gambar 5.Segmen 5 terjerat

\section{Ragam Gerak}

Ragam gerak dalam koreografi ini tidak memiliki istilah/nama khusus, hanya saja koreografer mebuat istilah/nama tersendiri untuk setiap ragam gerak utama yang digunakan, guna mempermudah penari dan koreografer berkomunikasi dalam berproses. Adapun beberapa nama geraknya, yaitu simbol gerak yang seolah-olah mendorong, gerak Jump (lompat) yaitu gerakan mengangkat tubuh dari suatu titik dengan tumpuan kedua kaki dan mendarat dengan kedua kaki. Gerak Kick (sepak) gerakan yang melambungkan salah satu kaki keudara. Koreografer juga menggunakan gerak-gerak tari modern seperti, Head Stand yaitu gerak yang bertumpu pada kedua tangan dengan posisi kedua kaki diatas. Salto depan adalah gerak menggulingkan badan kearah depan sebagai transisi dari gerak satu ke gerak selanjutnya. Gerak Kayang dilakukan dengan posisi kaki yang bertumpu pada lantai, posisi badan melengkung bagai busur. Gerak Split yaitu gerak yang memposisikan kedua belah kaki secara horizontal. Gerak Butterfly yaitu gerak lompat dengan kedua kaki ditendang lurus sambil berputar ke belakang.

\section{Gerak Jump (Lompat)}

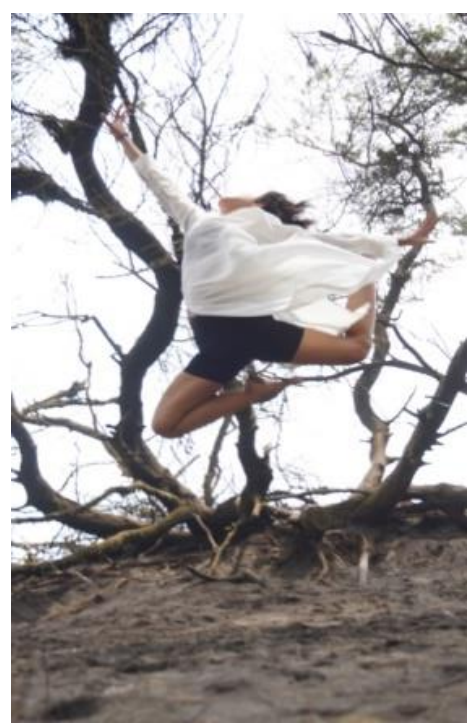

Gambar 6. Gerak lompat

2. Gerak Kayang

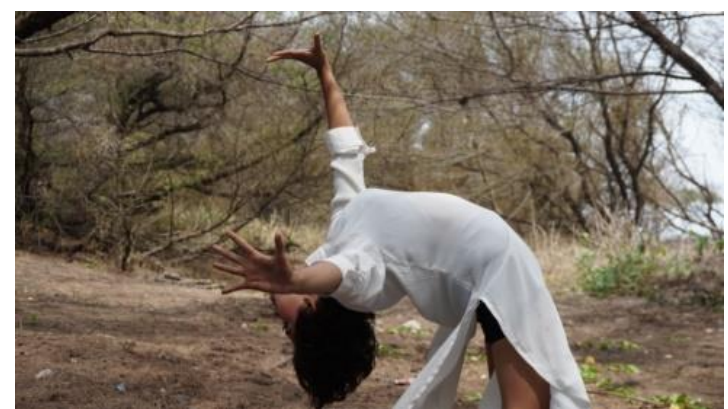

Gambar 7.Gerak Kayang

\section{Hand Stand}






Gambar 8.Hand stand

4. Gerak Butterfly

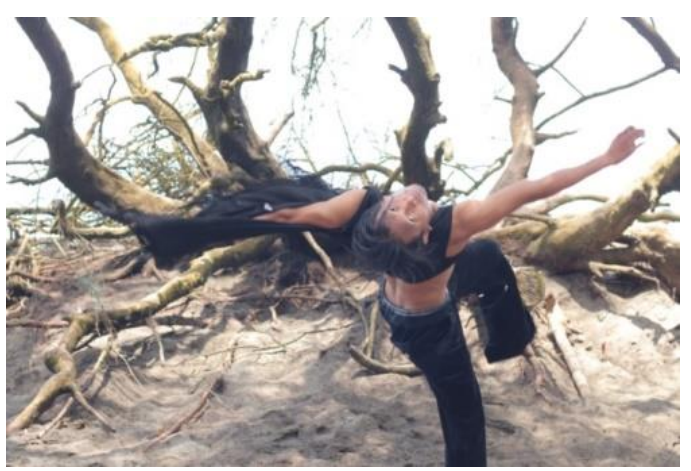

Gambar 9.Gerak Butterfly

5. Gerak simbol penolakan

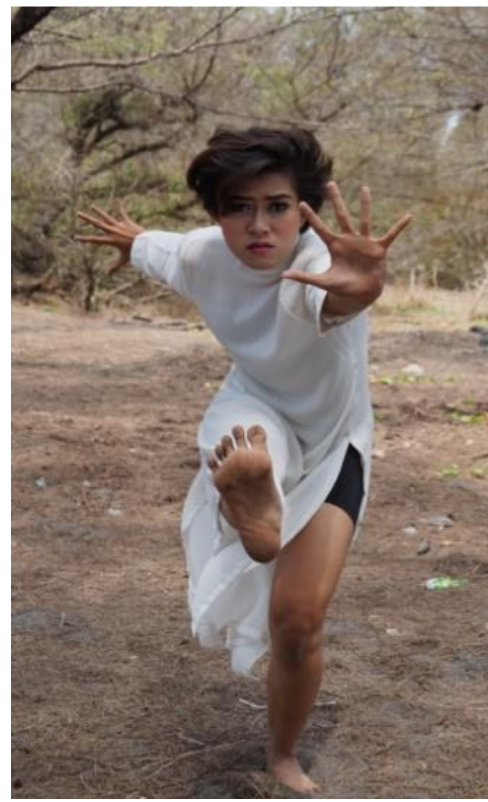

Gambar 10.Gerak penolakan
6. Gerak Kick

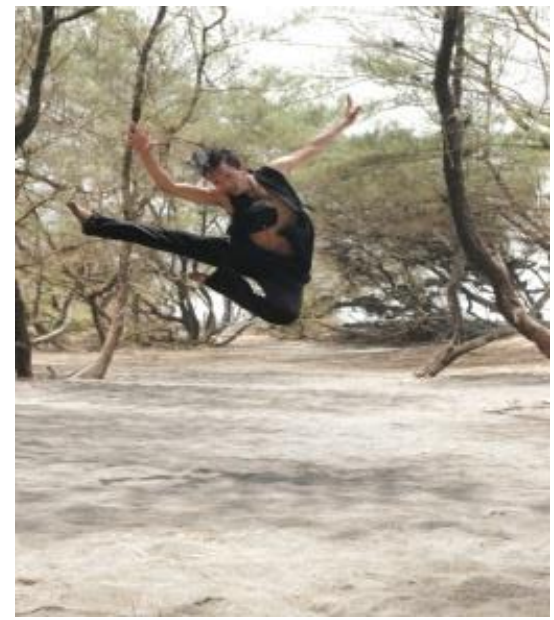

Gambar 11.Gerak Kick

\section{KESIMPULAN}

Penciptaan karya tari Terjerat terinspirasi dari seorang sahabat penulis yang datang berkunjung untuk berbagi keluh kesah kehidupan rumah tangganya yang belum lama terjalin. Pernikahan yang tidak didasari cinta kini membuat hubungan pernikahan mereka penuh dengan tekanan batin. Rasa menyesal dan terpukul karena harus meninggalkan sang kekasihnya yang sangat dia kasihi dan cintai terdahulu, yang berasal dari golongan masyarakat biasa hanya karena sebuah aturan adat dari keluarga bangsawan. Namun pada akhirnya ia menyadari bahwa aturan tersebut tidak menjamin kebahagiaan dalam sebuah hubungan pernikahan.

Adapun cerita tersebut penulis tuangkan ke dalam karya tari Terjerat, namun cerita yang ada di dalam karya tersebut tidaklah serupa dengan keadaan rumah tangga sahabatnya, melainkan penulis ingin menggambarkan bahwa takdir yang sudah ditentukan adalah lebih baik daripada keinginan setiap manusia.

\section{DAFTAR PUSTAKA}

Bastomi, S. (1988). Apresiasi Kesenian Tradisional. Semarang: IKIP Semarang Press.

Caturwati, E. (2009). Pesona Perempuan Dalam Sastra \& Seni Pertunjukan. Bandung: Sunan Ambu STSI Press.

Darmaprawira W.A, S. (2002). Warna Teori dan Kretivitas Penggunanya (2nd ed.). Bandung: Institut Teknologi Bandung.

Hadi, Y. S. (2003). Aspek - Aspek Dasar Koregrafi Kelompok. Yogyakarta: Manthili.

Hadi, Y. S. (2005). Sosiologi Tari Sebuah Pengenalan awal. Yogyakarta: Pustaka Yogyakarta.

Hadi, Y. S. (2007). Kajian Tari Teks dan Konteks. Yogyakarta: Pustaka Book Publisher.

Hadi, Y. S. (2007). New Dance Pendekatan 
Koreografi Nonliteral. Yogyakarta: Manthili. Hadi, Y. S. (2016). Koreografi : Bentuk-Teknik-Isi. Yogyakarta: Cipta Media.

Hawkins, A. M. (2003a). Creating Through Dance. (Y. S. Hadi, Ed.). Yogyakarta: Manthili.

Hawkins, A. M. (2003b). Moving From Within: A New Method for Dance. (I. W. DIbia, Ed.). Jakarta: MSPI.

Hoesin, M. (1970). Adat Atjeh. Banda Aceh: Dinas Pendidikan dan Kebudayaan Provinsi Daerah Keistimewaan Aceh.

Hurgronje, S. (1985). Aceh Di Mata Kolonialis. Jakarta: Yayasan Soko Guru.

Kuntowijoyo. (2006). Budaya dan Masyarakat. Yogyakarta: Tiara Wacana.

Raditya M.A, A. (2014). Sosiologi Tubuh. Yogyakarta: Kaukaba Dipantara.

Ramdhoni, M. H. (2011). Perempuan Penunggang Harimau. Bandar Lampung: Be Press.

Rusmini, O. (2007). Tarian Bumi. Jakarta: PT
Gramedia Pustaka Utama.

Setyobudi, D., \& Tim Abdi Guru. (2006). Seni Budaya Untuk SMP Kelas VII. Jakarta: Erlangga.

Smith, J. (1976). Dance Composition. (B. Suharto, Ed.). Yogyakarta: Ikalasti.

Soepomo, R. (2007). Bab-bab Tentang Hukum/Adat (17th ed.). Jakarta: PT Pradnya Paramita.

Sudiat, I. (2010). Asas-asas Hukum Adat Bekal Pengantar. Yogyakarta: Liberty.

Sugono, D. (2008). Kamus Bahasa Indonesia. Jakarta: Pusat Bahasa.

Sumardjo, J. (2000). Filsafat Seni. Badung: Institut Teknologi Bandung.

Triatmoko, B. B. (2012). Tarian Badai. Yogyakarta: Galang Press.

Yudiaryani, et. AL (Ed.). (2017). Karya Cipta Seni Pertunjukan. JB Publisher.

Zelfis, F. (2013). Bukan Perempuan Biasa. Yogyakarta: Buku Pintar. 